\title{
Heritage, health and wellbeing: Assessing the impact of a heritage focused intervention on health and wellbeing.
}

Erica Ander ${ }^{\mathrm{a}}$, Linda Thomson ${ }^{\mathrm{a}}$, Guy Noble ${ }^{\mathrm{b}}$, Anne Lanceley ${ }^{\mathrm{c}}$, Usha Menon ${ }^{\mathrm{c}}$ and Helen Chatterjee $^{\operatorname{ad}_{*}}$

${ }^{a}$ UCL Museums \& Collections, University College London, Darwin Building, Gower Street, London, UK; ${ }^{b}$ University College London Hospital Arts, University College London Hospitals NHS Foundation Trust, Ground Floor Rosenheim Wing, Grafton Way, London, UK; ${ }^{c}$ Dept of Women's Cancer, The UCL Elizabeth Garrett Anderson Institute for Women's Health, Maple House, 149 Tottenham Court Road, London, UK; ${ }^{d}$ Division of Biosciences, School of Life and Medical Sciences, University College London, Darwin Building, Gower Street, London, UK.

*Corresponding author. Email: h.chatterjee@ucl.ac.uk

Notes on contributors:

Erica Ander is Research Assistant on the UCL Heritage in Hospitals research project. She also works as a museum and heritage consultant specialising in visitor studies and audience research. Her research interests include qualitative methodologies to capture cultural outcomes and health and wellbeing issues in the museum sector. 
Linda Thomson is a Research Associate on the UCL Heritage in Hospitals project. Since obtaining her PhD in Psychology in 2001, Linda has worked as a lecturer and researcher specialising in memory and learning, and research methods.

Guy Noble, Arts Curator at UCL Hospitals, has worked in 'Arts in Health' since 1998. He was co-instigator of the research project Heritage in Hospitals and has extensive experience in hospital arts programming and is interested in the role that cultural organisations can play in health.

Anne Lanceley is a Senior Lecturer and Nurse Specialist, Institute for Women's Health, UCL. She combines a clinical role supporting women with cancer with running a clinically grounded research programme in the areas of symptom management, recovery after treatment and risk reduction for survivors.

Usha Menon is Professor of Gynaecological Cancer and Head of the Gynaecological Cancer Research Centre at the UCL Institute for Women's Health and Consultant Gynaecologist, UCLH NHS Trust, London. She is Principal Investigator on the UK ovarian cancer screening trials and on studies exploring ovarian cancer symptoms.

Helen Chatterjee is Deputy Director of Museums and Collections and Senior Lecturer in Biology at UCL. Her research interests include touch and object handling in health and wellbeing, and its pedagogical value in education. She edited 'Touch in Museums: Policy and Practice in Object Handling' and is Principal Investigator on the Heritage in Hospitals project. 


\title{
Heritage, health and wellbeing: Assessing the impact of a heritage focused intervention on health and wellbeing.
}

\begin{abstract}
Do museums and other heritage organisations have something to offer the healthcare sector? Do they have a role in improving health and wellbeing? Increasingly both heritage and healthcare organisations think they do. A broader definition of health including wellbeing and an emphasis on preventative medicine and multi-agency approaches to care within the UK's NHS (National Health Service), has facilitated the work of museums and galleries in this area. However, there are still few specific heritage programmes in healthcare organisations and very little evaluation of these. Here we present key findings from a qualitative evaluation of a heritage focused intervention carried out in a range of health care settings. The aim of the research project was to assess the impact on wellbeing of taking museum objects into hospitals and healthcare contexts.
\end{abstract}

Keywords: Health; Wellbeing; Object handling; Heritage intervention; Hospitals; Care homes. 


\section{Introduction}

The heritage sector is facing an unprecedented challenge and opportunity in being asked to contribute to arguably the most important issue affecting the word today, namely health and wellbeing. Galloway and Bell (2006) identified that Quality of Life (QoL) and wellbeing are being factored into public policy making and service delivery across much of the developed world. The UK's Museums, Libraries and Archive (MLA) Council's 'Outcomes framework' recognises the role heritage organisations have in contributing to adult health and general wellbeing, as well as children and young people's health. Numerous other policy directives and related research, such as that undertaken by the UK think-tank the New Economics Foundation $^{2}$, also acknowledge the important role culture and heritage play in wellbeing, both of individuals and communities.

The museum sector has increasingly been aware of the possibility of valuing their work in terms of health and wellbeing. Culture Unlimited, for example, created a manifesto for museums' potential benefit in the mental health field, Museums of the Mind ${ }^{3}$, showing that museum's strengths in 'perspective', memory, beauty, and being places of sanctuary could underwrite mental wellbeing. Since then, several initiatives by museums and galleries have focused on this area. Examples of good practice include Dulwich Picture Gallery's 'Good Times: Prescription for Art' programme (London, UK) and the 'Meet Me at MoMA (Museum of Modern Art, New York)' Alzheimer's Project ${ }^{5}$. Silverman's 'The Social Work of Musuems' (2010) considers museums as places of inspiration and healing, and proposes that museums can contribute to individual health in at least five ways: promote relaxation; immediate intervention to affect beneficial changes in physiology, emotions or both; encourage introspection; public health advocacy; and enhancing healthcare environments. 
Although there is considerable anecdotal evidence that the heritage sector makes an important contribution to improving health and wellbeing, and several examples of good practice robust empirical and qualitative evidence is scarcer ${ }^{6}$.

Arts-in-health also forms a background to the Heritage in Hospitals research and has a relatively high profile and support from the Arts Council England, Commission for Architecture and the Built Environment (CABE), and the Department of Health. Those working in the field of arts-in-health have been evaluating outcomes and justifying their role within health for several years. Staricoff's (2004) review of research in this area shows benefits to patients who received art interventions during their hospital stay. The review focuses on research which demonstrates arts role in the reduction of specific conditions, including pain, and other health benefits, rather than focusing on the more ambiguous 'wellbeing', which although contributing to health, remains a more individualised set of benefits. Arts-in-health has benefited from the increased emphasis by the UK's Department of Health on preventative medicine, multi-agency approaches and maintenance of wellbeing (UK Department of Health 2001, 2009; MLA 2004); a strategic background that this project capitalises on.

Here we describe an initiative entitled 'Heritage in Hospitals ${ }^{7}$ to take a university museum ${ }^{8}$ loan box service to a previously excluded audience located within hospitals and care homes. Funded by the UK's Arts and Humanities Research Council, the Heritage in Hospitals project drew upon research in the arts-in-health field and the concept of wellbeing. In addition museum learning theory, which is grounded in constructivist learning theory, underpinned the basic tenet of the research. The latter approach rejects the idea that learning is a simple matter of transferring content from stimulus to a receiver (learner) and suggests learning builds on individual experience, motivation and development whereby each learner 
constructs their own learning world (Hein 1998). Falk and Dierking's $(1992,2000)$ work on learning in museums is also influential in articulating health and wellbeing outcomes. Their research has resulted in the articulation of the Interactive Learning Model which proposes that the physical environment, the social context, the personal background of the museum visitor and subsequent experiences, all affect the learning that happens during a museum visit. These 'learning' concepts apply to wellbeing too. One could argue that people construct their own wellbeing from the situation they are in, the life resources they have and the experiences they encounter. When they have a museum encounter, whether in everyday life or in a healthcare institution, the impact the museum resource will have on their wellbeing should be affected by their physical environment, the social situation and their personal levels of interest, motivation and current wellbeing and health. However, wellbeing is an ambiguous term which has little agreement among disciplines on its definition or measurement (Galloway and Bell 2006; Ander et al. 2011; Thomson et al. 2011). A useful definition is that by the New Economics Foundation (NEF). NEF define wellbeing as 'most usefully thought of as the dynamic process that gives people a sense of how their lives are going, through the interaction between their circumstances, activities and psychological resources or 'mental capital' ' (NEF 2009). They suggest that in order to achieve wellbeing people need:

'a sense of individual vitality to undertake activities which are meaningful, engaging, and which make them feel competent and autonomous a stock of inner resources to help them cope when things go wrong and be resilient to changes beyond their immediate control. It is also crucial that people feel a sense of relatedness to other people, so that in addition to the personal, internally focused elements, people's social 
experiences - the degree to which they have supportive relationships and a sense of connection with others - form a vital aspect of well-being.' (NEF 2009, p.9)

This is further illustrated in Figure 1 where NEF have identified a series of indicators of personal and social wellbeing and suggest how these indicators interrelate.

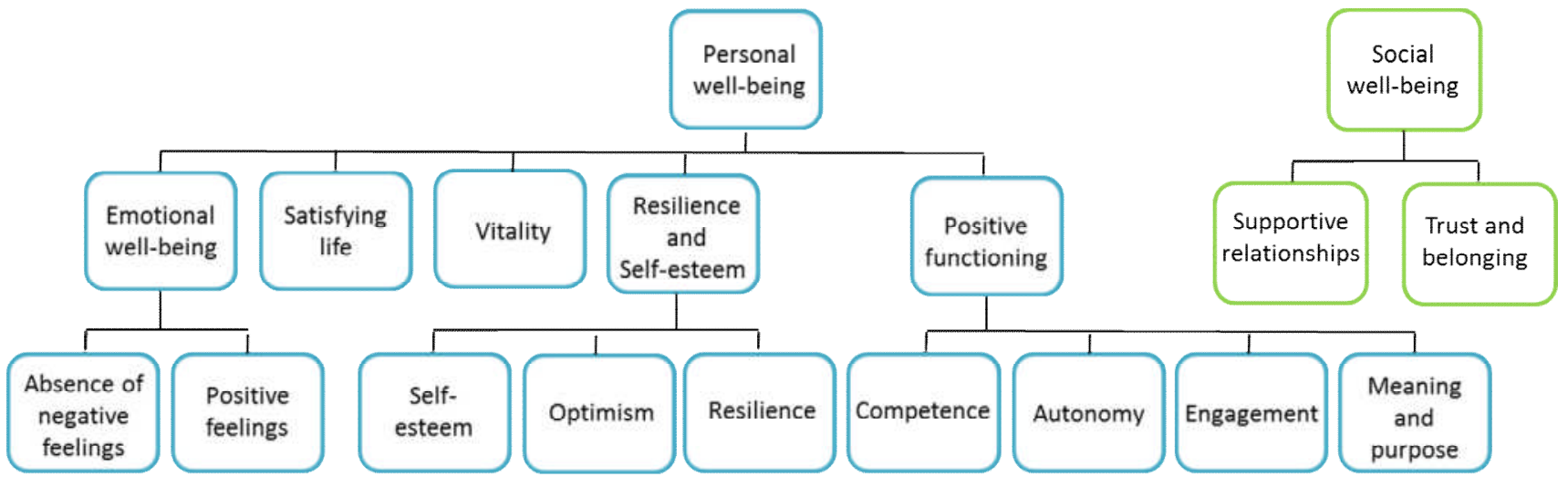

Figure 1. NEF's (2009) Indicator structure adapted from their national accounts framework ${ }^{2}$

Museums are facing similar challenges in measuring wellbeing to those experienced a few decades ago when trying to measure museum learning, in the sense that defining museum wellbeing and then capturing the individual's response is difficult and conflicts with the more formal methods used in traditional health measurements (Thomson et al. 2011).

\section{Methodology}

\section{Research Contexts}

The Heritage in Hospitals project worked within a number of hospitals and healthcare contexts, with the research aim to understand the therapeutic effects of a museum 
intervention on hospital and other healthcare users and to develop a protocol for effective engagement in healthcare contexts. Each research context had specific characteristics and this multi-centre research allowed for the contrast and comparison of results between different environments, staff systems and dominant medical conditions. Contexts included:

- A large central London acute hospital - oncology, gynaecological oncology, acute elderly and surgical wards

- A psychiatric hospital (Reading, UK) - elderly psychiatric ward

- Two neurological rehabilitation units (Oxford and London, UK) - inpatient and outpatient rehabilitation

- An elderly care home (London)

\section{Protocol}

The protocol involved delivering one-to-one facilitated museum handling sessions (Figure 2) using loan boxes from UCL Museums and Collections (or Oxford University Museum (OUM), UK, in one context). Boxes contained a range of objects representing geology, zoology, archaeology, art and Egyptology items. Objects were selected on the basis that they were small enough to be portable, had a tactile dimension and were sufficiently robust to be carried into the hospital/care home and handled without contravening clinical guidelines for infection control. The session comprised: recruitment (with voluntary opt out at any stage); explanation and consent; wash hands; baseline wellbeing measures; a facilitated session with the objects; wash hands; and second set of wellbeing measures. The session was recorded using a digital audio recorder. Following selected sessions an in-depth evaluative interview 
was undertaken by the facilitator. The sessions (excluding completing wellbeing scales, hand washing etc.) lasted from 15 to 75 minutes.

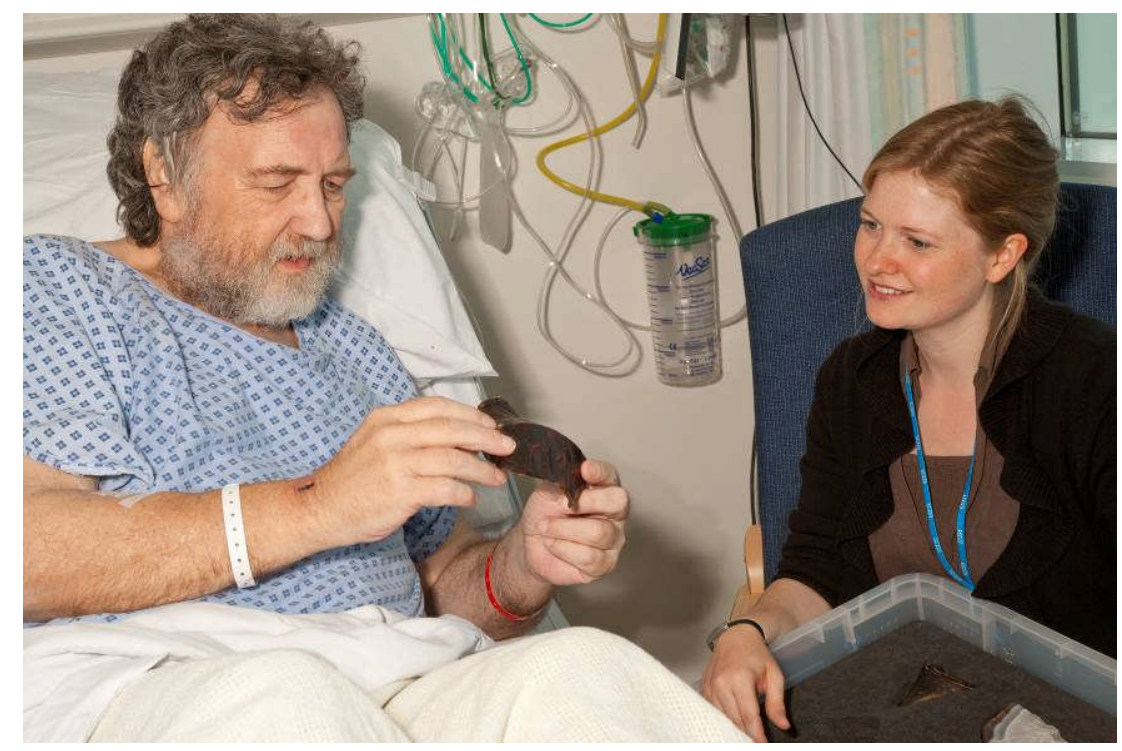

Figure 2. A museum object handling session at the bedside. Photograph (C) UCL Museums \& Collections.

The facilitators were two UCL Research Associates, one a museum professional, the other a trained psychologist, and two OUM museum professionals. Facilitators employed a standardised session protocol which offered ways of interacting with the patients and gave a prescribed order for the sessions so that most sessions were sufficiently similar to compare. At the elderly care home and the psychiatric hospital the protocol was adapted slightly, in consultation with staff, since group sessions, rather than one-to-one sessions, were conducted.

\section{Samples and recruitment}


Participant recruitment varied between research contexts (Table 1), according to the staff support and availability, number of beds, length of stay, medical conditions, physical or mental impairment level and the physical environment in each care setting.

Table 1. Samples and recruitment at five research contexts

\begin{tabular}{|l|l|}
\hline Healthcare context & Sample size (participants and sessions) \\
\hline $\begin{array}{l}\text { General Hospital (5 wards; } \\
\text { London) }\end{array}$ & 90 participants (12 male, 78 female); 91 one-to-one sessions \\
\hline $\begin{array}{l}\text { Neurological Rehabilitation } \\
\text { (London) }\end{array}$ & $\begin{array}{l}\text { 14 participants (7 male,7 female); } 30 \text { one-to-one sessions where } 5 \\
\text { participants took part in up to } 8 \text { sessions }\end{array}$ \\
\hline $\begin{array}{l}\text { Neurological Rehabilitation } \\
\text { (Oxford) }\end{array}$ & $\begin{array}{l}\text { 26 participants, (16 male, } 10 \text { female); } 26 \text { one-to-one sessions; } 4 \\
\text { group sessions }\end{array}$ \\
\hline $\begin{array}{l}\text { Elderly care home } \\
\text { (London) }\end{array}$ & 13 participants (4 male, 9 female); 13 one-to-one sessions \\
\hline $\begin{array}{l}\text { Psychiatric Hospital } \\
\text { Reading) }\end{array}$ & $\begin{array}{l}\text { 42 participants (13 male, } 29 \text { female); } 10 \text { group sessions where } 22 \\
\text { participants took part in } 2 \text { or more sessions }\end{array}$ \\
\hline
\end{tabular}

${ }^{\dagger}$ Note that not all sessions were analysed qualitatively.

\section{Data collection and Analysis}

Grounded theory method (Charmaz 2006; Corbin and Strauss 2008) data collection and analysis was employed to assess the impact of museum object handling within healthcare. This qualitative method identifies key points extracted from the data and the researcher defines codes on the basis of these points. Grounded theory method aims to produce new theory from the qualitative data by coding it inductively, and then using the techniques of constant comparison (in this case between sessions, contexts and participants), theoretical sampling and memoing to find relationships between phenomena, fully 'grounded' in the data. To collect qualitative data, audio recordings were made of the handling sessions, fieldnotes were written by facilitators to understand the contexts and the participant behaviours, and semi-structured interviews were conducted with patients, healthcare staff and museum professionals. A total of 51 handling session recordings were transcribed, with 
associated researcher fieldnotes for each session and additional interviews with several patients and eight healthcare staff.

Transcribed qualitative data from the 51 session recordings were entered into Nvivo, (qualitative analysis software) and firstly coded in an open manner using a line-by-line iterative process, which incorporates no underlying preconceptions of what the session might reveal, i.e. it is inductive rather deductive. This process generated codes for patient behaviour and session dialogue which led to the development of 'engagement' and its sub-codes, as a session process and its spectrum from low response to distraction through to stimulation. The coding also revealed a range of expressions by patients and staff which were associated with the concept of wellbeing; these codes ranged from 'new perspectives' to 'sense of identity'. The initial codes were reduced to core theme coding and memos were generated about the relationships between the themes. Constant comparison was used to compare sessions, patients and contexts.

\section{Findings}

The research identified 'engagement' processes and expressions of 'wellbeing' as key outcomes from museum handling sessions. There was a range of both phenomena evident in different sessions, depending on a complex mix of patient background, wellbeing (before session), personality, interest, medical condition and the strengths of the session itself. Engagement was found to be an important process for hospital patients because of the specific challenges they were facing including worry and anxiety (and even fear), boredom, pain, dwelling on illness, uncertainty, loss of pre-morbid identity, lethargy and depression and lack of stimulation. 
Most participants expressed improved wellbeing after the intervention, such as improved mood, calmed anxiety or a feeling of enhanced confidence. However, these improvements did not necessarily relate to sessions where we observed very high patient engagement. This was partly because the starting point of wellbeing was such an important factor in quick and deep engagement (rather than just the experience of the session itself) but also because participants had differing levels of ability in articulating their feelings and sense of wellbeing. For example, some participants said they were 'cheered up', or the session 'passed the time', while others were more deeply engaged in the session.

The heritage objects proved to be layered in their significance to patients and versatile in use, since we observed different patients accessed them sensorily, affectively and/or intellectually. The objects provided several ways through which patients could access these wellbeing benefits.

\section{Engagement with the objects}

The concept of engagement was used to describe the type of interaction and behaviour within a handling session. When coded some of the handling sessions appeared to have high levels of participant engagement. The term, which is used widely in learning and education, indicates an active motivation, a focus, involvement and concentration, the first steps to learning, but also, one could speculate, wellbeing. Engagement was not achieved in every session and it ran along a continuum from low response and interest, through distraction or the reduction of negative emotion; through stimulation or the increase in positive emotion, activity and thoughts, ultimately to a sense of wonder. A high level of engagement created a strong three-way dialogue and rhythm between objects, facilitator and participant. Participants answered and asked questions or made aesthetic, personal or intellectual 
comments. Dialogue consisted of participant questions, comments, links to their own objects, bringing in previous knowledge and experiences and using words of interest, surprise, fascination and amazement. Evidence of engagement, being drawn into the objects, was exhibited through attention, wonder, curiosity and interaction with the object, linking objects to their own lives and experience and cognitions:

'Its gorgeous, I like the bluish almost like the sky as it is now...My mother has a rose agate on her window sill and I've got a pink, a black, a brown and a dark blue. Its gorgeous, and lovely texture as well, cool and smooth, mmm like marble the same effect.'

Some participants, notably those from a neurological rehabilitation unit and mental health inpatients, did not always show signs of engagement, for example by facial expressions, speech, attention, but nonetheless appeared engaged. With these participants the researchers needed to be aware of more subtle behavioural signs and were helped by medical staff with background knowledge of the patients' symptoms and condition.

A person's engagement came from a variety of session elements: through touch; through vision or an aesthetic response; through learning about the significance of the object from the facilitator; from a personal recollection or connection to a particular object; or through a feeling of privilege or interest in general at being shown the objects. The handling sessions were found to sustain all of these doorways into object engagement depending on the competences and interests of participants. Object variety also dictated the direction of engagement. 


\section{Wonder}

One reaction that denoted strong engagement was coded 'wonder'. In these cases participants were deeply impressed by the objects they were touching or looking at and a sense of amazement overtook them; they became absorbed by the object. This is demonstrated by Julie, a female cancer patient:

'I love things like this. I could sit there for hours with things like this' 0051

"But there's something about this one [roman tile with paw print preserved in it] that's a little extra...

Finger!

Well I think not fingers but ...dog, dog paw

Or cat

Yeah could be a cat, but a bit small

I think a cat, what do you think?.....Because maybe dog....But this dog knows...I don't know the English...this dog didn't knows very lucky, because I now touching his pad

Yes he lives much longer than the other dogs! yeah

Yeah, everybody. Oh I see here very small things'

'it's about 9,500 years old, and it's an ancient artefact, it's actually an axehead

Good heavens... Its something in it?'

\section{Wellbeing outcomes}


Engagement in the objects provided stimulation and distraction, both highly important for wellbeing in the hospital context. Wellbeing, in various forms, was articulated directly by many participants and carers during and after the sessions, and participants mentioned: positive emotions and cheering up; giving new perspectives and thoughts about their lives; producing new learning, interest and desire to learn; initiating personal memories and recollections giving a renewed sense of identity; 'passing time much quicker'; creating a positive mood; bringing out a sense of vitality and energy to override depressive or lethargic feelings; relieving anxiety; it was something completely different and stimulated both social interaction and tactile senses which were in short supply in hospital (this was particularly noted by staff at the rehabilitation and psychiatric hospitals with long term patients). Patients mentioned factors such as their illness or impairment, their treatment, the hospital environment, and uncertainty of the future as decreasing their sense of wellbeing, as one woman described:

\footnotetext{
'Umm, a little [afraid]. Yeah....Because I don't know what's happening to me tomorrow.'
}

The hospital context was seen to be blank, boring and uncomfortable with long periods of waiting and introspection, and when simultaneously combined with illness, can strip someone of their more personal attributes, normal feelings and individuality (Watkins 1997). As Toni, a patient in the acute surgery unit, explained: 
'When you're actually in the hospital environment or when you've had two weeks to be by yourself and think about only yourself... and your life...It changes - It changes your view...And how you respond.'

The object sessions provided a creative opportunity for bringing back some of the pre-morbid self, through stimulation of the social, intellectual, experiential and emotional identity and distraction from the new medicalised, standardised and uncertain self-defined by the illness.

'But it's beautiful and it's a lovely, um, hue. And I like the shape of it and it's got curves on it and everything in here is squared off and clinical... and unattractive.'

Wellbeing, in many forms, was articulated directly by many participants and carers during and after the sessions:

'I think-I kind of think it's because healthy people go to museums....And here you are sick, but being brought these objects.

Yes. Bringing a little bit of the living world back up to this place.

Yes. That's right. That is absolutely, that's right.'

Table 2, below, provides a summary of our qualitative analysis which aimed at gaining an in depth understanding of the process of sessions and the impact of a session on an individual's sense of wellbeing. Interestingly our analytic codes map closely to accepted NEF wellbeing indicators. 
Table 2. Wellbeing outcomes derived from the Heritage in Hospitals study mapped onto NEF wellbeing indicators

\begin{tabular}{|c|c|c|}
\hline $\begin{array}{l}\text { Heritage in } \\
\text { Hospitals session } \\
\text { outcomes }\end{array}$ & Examples in data & $\begin{array}{l}\text { NEF wellbeing indicator } \\
\text { (see Figure 1) }\end{array}$ \\
\hline New perspectives & $\begin{array}{l}\text { 'Inspired. Very much so. It does - It does strangely reconnect you with life. They're dead } \\
\text { objects from thousands of years ago, but it does connect you with life.' } \\
\text { 'I think X said something that when you're dealing with something that's millions of years old } \\
\text { it puts your life into perspective and you've got something so beautiful here, and life you know } \\
\text { so she felt that the group helped her put things in perspective and brings people out and } \\
\text { removes them from their situation' Interview Prospect Park staff member }\end{array}$ & $\begin{array}{l}\text { Positive feelings, resilience, } \\
\text { meaning and purpose, } \\
\text { competence }\end{array}$ \\
\hline $\begin{array}{l}\text { Positive feelings } \\
\text { (Excitement, } \\
\text { enjoyment, } \\
\text { wonder, privilege, } \\
\text { luck, surprise) }\end{array}$ & $\begin{array}{l}\text { 'A very lovely stone....Very lovely, I love the colours and I like the pattern.' } \\
\text { 'It's also a point for a conversation as well. Otherwise you just keep talking about some things. } \\
\text { You just look at things and question: 'Oh look at that! Where does it come from?' It's nice to } \\
\text { see these things in the hospital....It doesn't have to be just a place where you feel awful, you } \\
\text { know. It can be a place where in a certain way people are looking after you and they help you } \\
\text { and...you know.' }\end{array}$ & $\begin{array}{l}\text { Positive feelings, } \\
\text { engagement, vitality }\end{array}$ \\
\hline $\begin{array}{l}\text { Learning (including } \\
\text { skills and confidence) }\end{array}$ & $\begin{array}{l}\text { 'It teaches you a bit more about observation, so you know, I'm sort of thinking now, what on } \\
\text { earth can I say about this? But you've got to really look at something for a while haven't you?' } \\
\text { 'That's it, as you come to see, as you show me, I know the history or some of it, if I came } \\
\text { across it, another thing in the future, I would think I think I've seen this thing before, and I } \\
\text { would make my mind up that this was something important.' }\end{array}$ & $\begin{array}{l}\text { Engagement, competence, } \\
\text { self esteem }\end{array}$ \\
\hline Energy, alertness & $\begin{array}{l}\text { 'alert, yes more alert than ever, ever, ever..... determined to go places, look up things...that's } \\
\text { got the active going it really has' } \\
\text { ' - you can just sit and while the time away in the living room and not generate thoughts! A lot } \\
\text { of people can't read, when they're here, because then your own thoughts come in, but this it's }\end{array}$ & $\begin{array}{l}\text { Vitality, meaning and } \\
\text { purpose, lack of negative } \\
\text { feelings }\end{array}$ \\
\hline
\end{tabular}




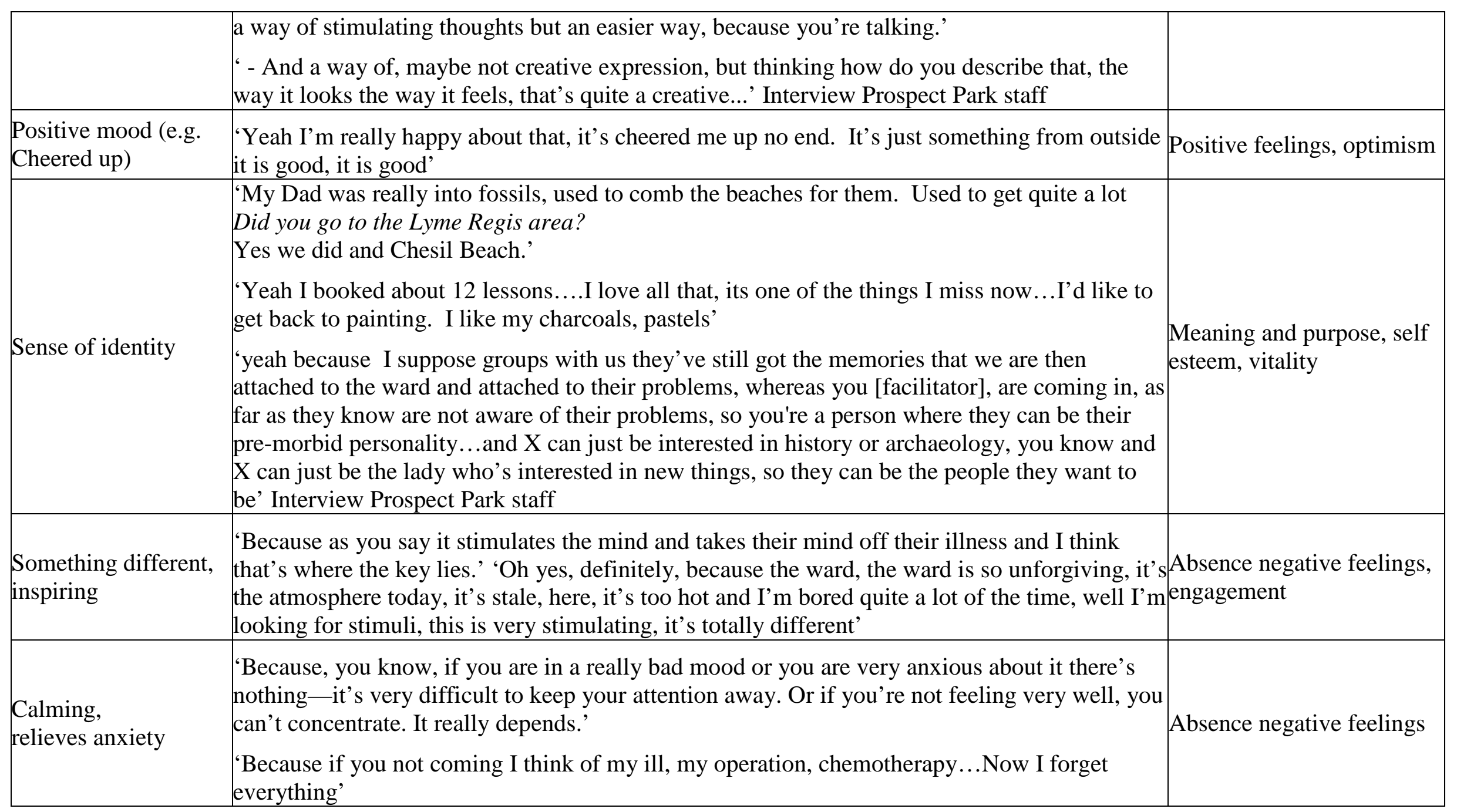




\begin{tabular}{|l|l|l|}
\hline Passing time & 'It's been great, been like spending an afternoon at the museum.' & Absence negative feelings \\
\hline Social Experience & $\begin{array}{l}\text { 'but even the ones who didn't necessarily contribute much,... being part of the group } \\
\text { and handling items, it got them away from being stuck in the room or maybe the TV } \\
\text { room where they didn't really want to be, the boredom of that, and having that } \\
\text { structure and the social thing I think it was quite beneficial for them' Interview, } \\
\text { Prospect Park staff }\end{array}$ & $\begin{array}{l}\text { Competence, autonomy, } \\
\text { vitality, self esteem, } \\
\text { supportive relationships }\end{array}$ \\
\hline Tactile experience & $\begin{array}{l}\text { 'and the nature of the ward, is we've not got a lot of things around for them to be } \\
\text { touching, just because if we've got someone's who's a bit aggressive we don't want } \\
\text { them to be throwing things, vases and stuff, so maybe the tactile aspect, just having } \\
\text { new textures to touch' Interview, Prospect Park staff } \\
\text { 'Oh, I see. Can you actually feel like the little dents? Like the actual texture of the } \\
\text { starfish? You can still feel it.' } \\
\text { 'Something like an earthenware but, er, um, it's so cool and smooth, it's beautifully } \\
\text { smooth, it's a wonderful piece.' }\end{array}$ & $\begin{array}{l}\text { Competence, autonomy, } \\
\text { positive feelings }\end{array}$ \\
\hline
\end{tabular}




\section{Conclusions}

The Heritage in Hospitals research has described the types of engagement and wellbeing benefits possible from a museum intervention in a healthcare context. The session recordings, patient interviews and research field note observations showed that, once patient participants were engaged, museum objects provided unique and idiosyncratic routes to stimulation and distraction. The data showed that patients used the heritage objects combined with tailored and easy social interaction, sensory stimulus and learning opportunities to tap into concerns about identity, emotions, energy levels and motivation. Participant's reactions to handling museum objects gave an insight into why heritage objects in particular (rather than pictures or non-heritage objects) produce engagement, feelings (positive and negative) and wellbeing benefits. For example, heritage objects have usually been collected because they are significant. Revealing this significance can drive wonder and fascination. It can also prompt memories and previous knowledge they did not get from the tactile encounter. Furthermore, heritage objects are not usually allowed to be touched and if the participant knows that it can invoke a sense of privilege. 'Interesting', 'completely different' and yet able to reach into participants' previous experiences, knowledge and skills, museum sessions, quickly drew people into the objects in some cases and in doing so drew people out of their illness and environment. This happened across all the care settings where the project took place. The multi-centre research also showed that a museum handling session is a versatile and accessible 'tool' to improve wellbeing for long and short term patients, and sufferers of mental and physical ill health alike. Further work needs to be undertaken to assess how far improved wellbeing as a result of object handling is sustained and sustaining for patients. The Heritage in Hospitals project provides a model for museum work to enhance wellbeing in health care settings. Different adaptations to sessions were needed with different patient 
groups and the work can be time-intensive for poorly-funded museums. Care of heritage collections and the need for trained facilitation also need to be thought about for such projects to work.

There is further work to be done to make health and wellbeing a mainstream part of museum programming, but with more projects like Heritage in Hospitals running, and more funders interested in health and wellbeing, this type of outreach work may well be seen on many museums' programming plans and is a powerful way of providing access to previously excluded audiences. Given the future funding landscape and the changing emphasis towards to individual health and wellbeing across social policy, the Heritage in Hospitals project, and others like it, indicate that the heritage sector has a significant role to play in improving health and wellbeing. As outlined in Chatterjee et al (2009) heritage has the potential to play a transitional and transformational role in healthcare and wellbeing. A closer engagement between the heritage and health sectors could involve partnerships with Primary Care Trusts, Community Health partnerships and third sector organizations such as The Alzheimer's Society. In the current economic climate issues such as worklessness, economic deprivation and failing health are likely to become more acute. The heritage sector can seek to address these challenges through raising aspirations, developing self-confidence and promoting mental and general health care (Chatterjee et al. 2009). In conclusion, closer links between heritage and social care organizations, such as hospitals or care homes, offers significant mutualistic benefits and should not be underestimated.

\section{Acknowledgements}

The authors gratefully acknowledge the support of the UK Arts and Humanities Research Council who funded this research (Award number: AH/G000506/1). Part of the work was carried out within the 'women's health theme' of the UCLH and UCL NIHR Comprehensive 
Biomedical Research Centre supported by the UK Department of Health. We are grateful to all of the patients, care home residents and staff who participated in this project.

\section{Notes}

1. Museums Libraries and Archives, 2010.

2. New Economics Foundation, 2009, p.21.; Bacon et al, 2010

3. Culture Unlimited, 2008, http://www.cultureunlimited.org/museums-of-the-mind.php

4. 'This is Living' Good Times: Art for Older People at Dulwich Picture Gallery, Harper and Hamblin, Oxford Institute of Ageing Report.

5. 'Meet me' Making Art Accessible to People with Dementia, The Museum of Modern Art, Rosenberg et al. 2009.

6. Burns Owen Partnership, 2005.

7. Heritage in Hospitals project website, http://www.ucl.ac.uk/museums/research/touch/wellbeing

8. UCL Museums \& Collections, website, http://www.ucl.ac.uk/museums/

9. Quotations are directly from participants, although anonymised with their research sample number/a pseudonym; in all quotations the italicised text is from the facilitator and the normal text is the participant.

\section{References}

Ander, E., Thomson, L., Lanceley, A., Menon, U., Noble, G. and Chatterjee, H.J., 2011. 
Generic Wellbeing Outcomes: Towards a conceptual framework for wellbeing outcomes in museums. Museum Management and Curatorship, 26 (3), 237-259.

Bacon, N., Brophy, M., Mguni, N., Mulgan, G. and Shandro, A., 2010. The State of Happiness: Can public policy shape people's wellbeing and resilience? London: The Young Foundation.

Burns Owen Partnership, 2005. New Directions in Social Policy: Developing the evidence base for museums, libraries and archives in England. London: MLA.

Chamaz, K., 2006. Constructing Grounded Theory. London: Sage

Corbin, J. and Strauss, A., 2008. Basics of Qualitative Research 3e London: Sage.

Chatterjee, H. J., Vreeland, S. and Noble, G., 2009. Museopathy: Exploring the Healing Potential of Handling Museum Objects. Museum and Society. 7(3), 164-177.

EuroQol Group. 1990. EuroQol: A new facility for the measurement of health related quality of life. Health Policy, 16, 199-208.

Galloway, S. and Bell, D., 2006. Quality of Life and Well-being: measuring the benefits of culture and sport: literature review. Scottish Government. Available at: http://www.scotland.gov.uk/Publications/2006/01/13110743/0

Falk, J. and Dierking, L., 1992. The Museum Experience. Ann Arbor: Whalesback Books.

Falk, J. and Dierking. L., 2000. Learning from museums: Visitor experiences and the 
making of meaning. Walnut Creek, CA: Altamira.

Harper, S. and Hamblin, K., 2010. This is Living. London: Dulwich Picture Gallery.

Hein, G., 1998. Learning in the Museum. London: Routledge

Museums, Libraries and Archives Council. 2004. New Directions in Social Policy: Health Policy for Museums, Libraries and Archives. London: MLA. Available at:

http://www.mla.gov.uk/what/publications/ /media/Files/pdf/2004/ndsp_health.ashx

Museums, Libraries and Archives Council. 2010. Inspiring Learning for All. Available at: http://www.inspiringlearningforall.gov.uk/

Museums, Libraries and Archives Council. 2010. Outcomes Framework for museums, libararies and archives. London: MLA. Available at:

http://www.mla.gov.uk/what/raising_standards/improvement/ /media/Files/pdf/2008/outcome s_framework_v2.ashx

New Economics Foundation. 2004. The Power and Potential of Wellbeing: Measuring Young People's Wellbeing in Nottingham NEF. Available at:

http://www.neweconomics.org/publications/power-and-potential-well-being-indicators

New Economics Foundation. 2009. National Accounts of Wellbeing: What is Wellbeing? Available at: http://www.nationalaccountsofwellbeing.org/learn/what-is-well-being.html 
Rosenberg, F., Parsa, A., Humble, L. and McGee, C., 2009. Meet Me: Making Art Accessible to People with Dementia. New York: Museum of Modern Art.

Silverman, L., 2010. The Social Work of Museums. London: Routledge.

Staricoff, R., 2004. Arts in health: a review of the medical literature. London: Arts Council England.

Thomson, L., Ander, E., Menon, U., Lanceley, A. and Chatterjee, H.J., 2011. Evaluating the therapeutic effects of museum object handling with hospital patients: A review and initial trial of wellbeing measures. Journal of Applied Arts and Health, 2 (1), 37-56.

UK Department for Communities and Local Government. 2010 Local priorities online. Available at: http://www.localpriorities.communities.gov.uk/

UK Department of Health. 2001. Making it Happen: a guide to delivering mental health promotion. Available at: http://www.dh.gov.uk/en/Publicationsandstatistics/Publications/PublicationsPolicyAndGuidan ce/DH_4007907

UK Department of Health with Arts Council, England. 2007. A Prospectus for Arts and Health. Available at: http://www.artscouncil.org.uk/publication_archive/a-prospectus-for-artsand-health/ 
UK Department of Health. 2009. New Horizons: a shared vision for mental health. Available at: http://www.newhorizons.dh.gov.uk/assets/2010-02-04-299060_NewHorizons_acc2.pdf Watson, D., L. Clark and A. Tellegen. 1988. Development and validation of brief measures of positive and negative affect: The PANAS scales. Journal of Personality and Social Psychology, 54: 1063-70.

Watkins, A., 1997. Mind-body medicine: A clinician's guide to pychoneuroimmunology. New York: Churchill Livingstone. 